\title{
Association of exposure to polycyclic aromatic hydrocarbons (estimated from job category) with concentration of 1-hydroxypyrene glucuronide in urine from workers at a steel plant
}

Daehee Kang, Nathaniel Rothman, Soo-Hun Cho, Hyun Sul Lim, Ho-Jang Kwon, Sun-Min Kim, Brian Schwartz, Paul T Strickland

Division of

Occupational Health,

Department of

Environmental Health

Sciences, Johns

Hopkins School of

Hygiene and Public

Health, Baltimore,

MD, USA

D Kang

B Schwartz

P T Strickland

Occupational Studies

Section, Epidemiology

and Biostatistics

Program, National

Cancer Institute,

Bethesda, MD, USA

N Rothman

Department of

Preventive Medicine,

Seoul National

University, Seoul,

Korea

S-H Cho

H-J Kwon

S-M Kim

Department of

Preventive Medicine,

Dongguk University,

Pohang, Korea

H S Lim

Present Address: Hazard Evaluation and

Technical Assistance

Branch, NIOSH

Cincinnati, OH 45226,

USA

D Kang

Correspondence to:

Dr Paul Strickland,

Department of

Environmental Health

Sciences, Johns Hopkins

School of Public Health,

615 North Wolfe Street,

Baltimore, MD 21205 ,

USA.

Accepted 25 May 1995

\section{Abstract}

Objectives-Increased risk of lung cancer has been associated with employment in the steel industry. This association is thought to be due in part to increased concentrations of polycyclic aromatic hydrocarbons (PAHs) in air found in this work environment. Measurement of PAH metabolites in human urine provides a means of assessing individual internal dose of PAHs. This study examined the relative contribution of occupation and smoking to urinary concentration of 1hydroxypyrene glucuronide (1-OHPG) among a group of workers at a steel plant. Methods-Concentrations of 1-OHPG in urine from 44 workers with jobs associated with increased air concentrations of PAHs and 40 workers with jobs with low or no exposure to PAHs were measured. 20 workers in each group were not current smokers. Urinary 1-OHPG was measured by synchronous fluorescence spectroscopy after immunoaffinity chromatography specific for PAH metabolites.

Results-Mean (SEM) urinary 1-OHPG concentration was $2 \cdot 16(0.42) \mathrm{pmol} / \mathrm{ml}$ urine among the 44 occupationally exposed workers compared with 0.38 $(0 \cdot 05)$ among the 40 workers with no or low exposure $(P<0.0001)$. Mean urinary 1-OHPG concentration was $1.82(0.41)$ $\mathrm{pmol} / \mathrm{ml}$ urine among the 44 current smokers compared with $0.75 \quad(0.20)$ among the 40 non-smokers $(P<0.005)$. Mean 1-OHPG concentrations in nonsmokers were $0.26(n=20), 0 \cdot 70(n=15)$, and $2.84 \mathrm{pmol} / \mathrm{ml}$ urine $(n=5)$ for strata of exposure to PAHs (no or low, mid, and high) based on job category; the corresponding values in smokers were $0.55(\mathrm{n}=$ 20), $0.94(\mathrm{n}=12)$, and $4.91 \mathrm{pmol} / \mathrm{ml}(\mathrm{n}=$ 12), respectively. Multiple linear regression showed significant differences between subjects in different PAH exposure strata and between smokers and non-smokers. Both smoking and occupational exposure to PAHs were associated with increased concentrations of 1OHPG in urine. Amounts of foods containing PAHs ingested by this group of workers were relatively low and did not contribute significantly to urinary 1OHPG concentrations.

Conclusions-These results indicate that 1-OHPG is a common urinary metabolite in people with recent occupational exposure to PAHs and is associated with both job category and estimated stratum of PAH exposure.

\section{(Occup Environ Med 1995;52:593-599)}

Keywords: polycyclic aromatic hydrocarbons; 1hydroxypyrene glucuronide; urinary biomonitoring

Polycyclic aromatic hydrocarbons (PAHs) are produced during incomplete combustion of organic materials, and humans are exposed to these compounds from a variety of occupational, environmental, personal, and dietary sources. ${ }^{12}$ In the steel industry, increased air concentrations of PAHs are found in several work areas, particularly near blast furnaces and coke ovens. ${ }^{3}$ Urinary biomarkers of PAH exposure or internal dose have been proposed as a means of assessing recent exposure to these compounds. Urinary metabolites of PAHs are useful because of their ease of collection and extensive chemical characterisation. Becher and Bjørseth ${ }^{4}$ developed an analytical procedure to measure PAHs in human urine by chemical reduction of metabolites to parent PAHs with subsequent analysis by high performance liquid chromatography (HPLC) with fluorescence detection. Application of this method to urine samples from workers at aluminum plants ${ }^{5}$ and coke ovens ${ }^{6}$ did not show differences in urinary PAH concentrations between exposed workers and non-exposed controls.

After Keimig et al reported that 1-hydroxypyrene was a major metabolite of the cocarcinogen pyrene in pig urine ${ }^{7}$ Jongeneelen et $a l^{8-15}$ conducted a series of studies evaluating the excretion of 1-hydroxypyrene in rodent and human urine. They measured this metabolite in urine of people occupationally exposed to PAHs (coke-oven workers, petroleum coke handlers, creosote impregnating plant workers) or therapeutically exposed (psoriatic patients treated with mineral coal tar and patients with eczematous dermatitis undergoing coal tar treatment)..$^{9-16}$ Excretion 
of 1-hydroxypyrene occurred fairly rapidly (6-35 h) after exposure to coke oven emissions. ${ }^{9}$ These studies analysed urine after enzymatic hydrolysis treatment with $\beta$-glucuronidase or aryl-sulphatase to convert conjugated metabolites to 1-hydroxypyrene. We have recently developed a sensitive and specific method to measure 1-hydroxypyreneglucuronide (1-OHPG), the most abundant water soluble metabolite of pyrene in unhydrolysed urine.$^{17}$ To investigate the usefulness of this metabolite as a potential biomarker of occupational exposure to PAHs, we examined the relative contribution of occupation and smoking on urinary concentration of 1OHPG among a group of steel plant workers in a modern steel production factory. As different job categories within the steel industry are associated with exposure to varying concentrations of combustion product and risk of lung cancer, ${ }^{18}$ we examined urinary $1-O H P G$ concentration in workers with various jobs within the steel plant.

\section{Methods}

STUDY POPULATION

Study participants were employees at a modern steel plant located in South Korea. Urine samples were collected in conjunction with an annual physical examination after informed consent was provided to participate in the study. Urine samples $(40 \mathrm{ml})$ were frozen at $-70^{\circ} \mathrm{C}$, shipped to the United States on dry ice, and stored at $-70^{\circ} \mathrm{C}$ for four months before analysis. The 44 exposed workers had jobs that dealt with the processing of raw materials and steel including coal, coke, iron ore, molten iron, and molten steel. The 40 control subjects worked mainly in office areas that are located about $2 \mathrm{~km}$ from the iron and steel making plant. Also included in this control group were non-office support workers in the plant that included construction and transportation workers. Concurrent personal air sampling information was not available; however, personal air measurements were available from one year before the urine collection in a group of workers at the coke plant only.

Job categories were used to assign to the workers relative PAH exposures - that is, no, low, mid, or high PAH exposure based on the scheme published by Bjørseth and Becher ${ }^{3}$ (table 1). There were 20 non-smokers in the combined mid and high exposure groups and

Table 1 Polycyclic aromatic hydrocarbon job exposure categories

\begin{tabular}{lrl}
\hline fob category & $n$ & Exposure category \\
\hline Office & 33 & None \\
Construction or & 7 & Low \\
$\quad$ transport & 5 & Mid \\
Continuous casting & 10 & Mid \\
Steel production & 12 & Mid \\
Iron production & 8 & High \\
Blast furnace & 9 & High \\
Coke oven & 9
\end{tabular}

¿Based on Bjørseth and Becher categorisation. Low $=<0.01 \mu \mathrm{g} \mathrm{BaP} / \mathrm{m}^{3} ; \mathrm{Mid}=0.01-1.0 \mu \mathrm{g} \mathrm{BaP} / \mathrm{m}^{3} ; \mathrm{High}=$
$>1.0 \mu \mathrm{g} \mathrm{BaP} / \mathrm{m}^{3}$.
20 non-smokers in the combined no and low exposure groups. A self-administered questionnaire was used to obtain subject information that included smoking habits, job history, major diseases, dietary habits, drug use, and possible use of personal protective equipment. Although personal protective equipment was available in some of the mid and high exposure groups, its use was difficult to confirm by questionnaire.

ASSAY FOR 1-HYDROXYPYRENE GLUCURONIDE The 1-OHPG was measured in urine with a recently developed assay. ${ }^{17}$ Urine samples (2 ml) were treated with $0.1 \mathrm{~N} \mathrm{HCl}\left(90^{\circ} \mathrm{C}, 60\right.$ $\mathrm{min}$ ), neutralised, and loaded onto Sep-pak C18 cartridges (Waters). After washing with $30 \%$ methanol, the relatively non-polar metabolites were eluted with $4 \mathrm{ml}$ of $80 \%$ methanol and the volume of eluate was reduced to $0.5 \mathrm{ml}$ by evaporation. The concentrated samples were diluted to $4 \mathrm{ml}$ with $15 \mathrm{mM}$ phosphate buffered saline (PBS) and loaded on to immunoaffinity columns prepared with $0.8 \mathrm{ml}$ cyanogen bromide activated sepharose 4B (Sigma) coupled with monoclonal antibody $8 \mathrm{E} 11$ that recognises several PAH-DNA adducts and metabolites. ${ }^{19}$ We have previously shown that 1-OHPG binds to these columns. ${ }^{17}$ After washing the columns three times with $4 \mathrm{ml}$ of $15 \mathrm{mM}$ PBS, compounds bound to the monoclonal antibody 8E11 were eluted with $2 \mathrm{ml}$ of $40 \%$ methanol in three fractions. Eluate fractions were analysed by synchronous fluorescence spectroscopy with a Perkin-Elmer LS50 fluorescence spectrometer. The excitationemission monochromators were driven synchronously with a wavelength difference of $34 \mathrm{~nm}$. Under these conditions 1-OHPG produces a characteristic fluorescence emission maximum at $381 \mathrm{~nm}$ (347 $\mathrm{nm}$ excitation). ${ }^{17}$ Fluorescence intensity was used to quantify 1-OHPG; the limit of detection was 0.03 $\mathrm{pmol} / \mathrm{ml}$ urine. The coefficient of variation of the assay was $8 \%-10 \%$ during the period of sample analysis. A subset of samples was further purified by HPLC then by synchronous fluorescence spectroscopic analysis of individual fractions to confirm the identity of the fluorophore as already described. ${ }^{17}$

\section{DATA ANALYSIS}

Log transformation of urinary 1-OHPG concentrations normalised the frequency distribution in the exposed and control study groups. Log of 1-OHPG concentration was the outcome variable in all analyses. Summary data are presented as mean (SEM) and median (range). Group differences between exposed and controls, or smokers and non-smokers were tested with Student's $t$ test. Pearson correlation was used to test the relation between urinary 1-OHPG concentration and stratum of PAH exposure or number of cigarettes smoked a day. Analysis of variance was used to test for overall differences in 1-OHPG concentrations among job categories. Duncan's multiple range test was used to compare differences between job categories. Multiple 
linear regression was used to test for group differences between strata of PAH exposure or between smoker groups, to test for linear trends of each exposure variable, and to evaluate potential interaction and confounding. Two sided statistical tests were used throughout; $P$ values $<0.05$ were considered to be significant.

\section{Results}

Before analysing the samples, job categories were used to assign exposure to PAHs based on the published scheme of Bjørseth and Beche $^{3}$ (table 1). The high PAH exposure stratum included blast furnace $(n=8)$ and coke plant $(n=9)$ workers; the mid PAH exposure stratum included continuous casting workers $(n=5)$, steel production furnace workers $(n=10)$, and iron production workers $(n=12)$ who mainly transported pig iron from the blast furnace to the steel making furnace; and the no or low PAH exposure stratum included office workers $(n=33)$ and construction or transportation workers $(n=7)$. Distribution of smoking was similar in the exposed and no or low exposure groups with

Table 2 Demographic characteristics of steel plant workers

\begin{tabular}{llr}
\hline & $\begin{array}{l}\text { No or low } \\
\text { exposure } \\
\text { group }(n(\%)) \\
n=40\end{array}$ & $\begin{array}{l}\text { Exposed } \\
\text { group }(n(\%)) \\
n=44\end{array}$ \\
Characteristic & $17(42 \cdot 5)$ & $5(11 \cdot 4)$ \\
\hline Age: & $17(42 \cdot 5)$ & $25(56 \cdot 8)$ \\
$19-29$ & $6(15 \cdot 0)$ & $13(29 \cdot 5)$ \\
$30-39$ & & \\
$\geqslant 40$ & $20(50 \cdot 0)$ & $20(45 \cdot 5)$ \\
Smoking: & $13(32 \cdot 5)$ & $13(29 \cdot 5)$ \\
$\quad$ Never or former & $7(17 \cdot 5)$ & $11(25 \cdot 0)$ \\
Current & & \\
5-19/day & $33(82 \cdot 5)$ & \\
$\geqslant 20 /$ day & $7(17 \cdot 5)$ & $5(11 \cdot 4)$ \\
Job category & & $10(22 \cdot 7)$ \\
Office & & $12(27 \cdot 3)$ \\
Construction or transport & $8(18 \cdot 2)$ \\
Casting & $9(20 \cdot 4)$ \\
Steel production & & \\
Iron production & & \\
Blast furnace & & \\
Coke plant & & \\
\hline
\end{tabular}

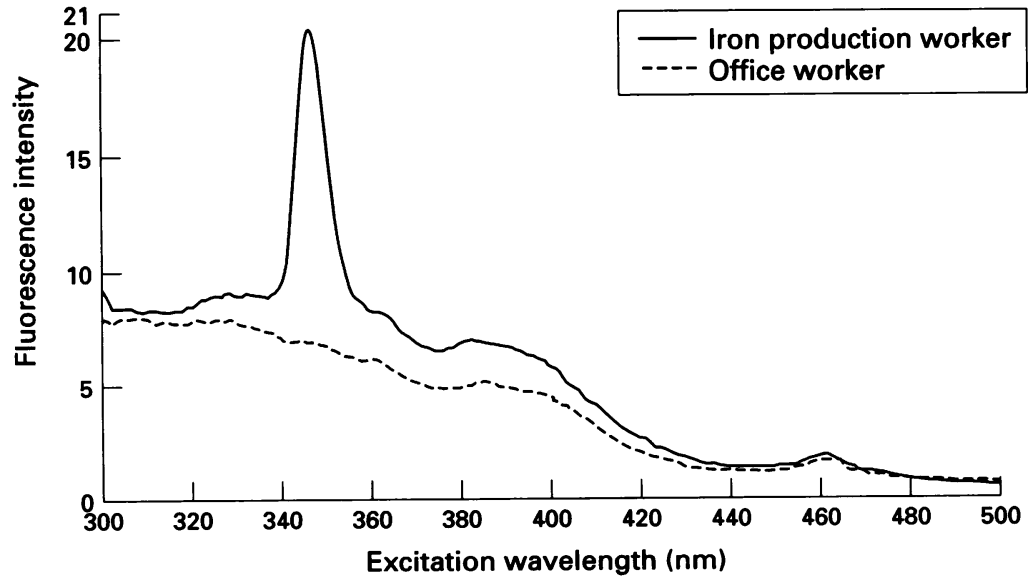

Figure 1 Representative synchronous fluorescence spectrum of immunoaffinity-purified urine samples from an iron production worker and an office worker. about $50 \%$ non-smokers in each group and about $20 \%$ one pack a day smokers (table 2 ). The age distribution between the exposed and no or low exposure group was different $(P=$ 0.008 by ANOVA). Age was not found to be significantly associated with 1-OHPG in multiple regression analysis (see results).

Synchronous fluorescence spectroscopy analysis of immunoaffinity purified urine samples indicated a fluorescence excitation maximum (347 $\mathrm{nm}$ ) characteristic of the pyrene moiety in 1-OHPG in 82 of the 84 samples analysed (fig 1 shows an example of detectable and non-detectable samples). The HPLC separation of a subset of 20 urine samples followed by synchronous fluorescence spectroscopic analysis of fluorescent fractions indicated that $98 \%-100 \%$ of the pyrene moiety fluorescence was due to 1-OHPG (data not shown). Non-detectable samples were assigned a value of $0.015 \mathrm{pmol} / \mathrm{ml}$ urine which is half the limit of detection of the assay.

Urinary 1-OHPG concentrations of subjects with jobs associated with exposure to combustion products were compared with the no or low exposure group (fig 2). The mean (SEM) 1-OHPG concentration in exposed workers $(2.16(0.42) \mathrm{pmol} / \mathrm{ml}, \mathrm{n}=44)$ was significantly greater than that of no or low exposure group $(0.38(0.05) \mathrm{pmol} / \mathrm{ml}, \mathrm{n}=40)$ ( $\mathrm{P}<0.0001$ by $t$ test). Also, the mean (SEM) 1-OHPG concentration in current smokers $(1.82(0.41) \mathrm{pmol} / \mathrm{ml}, \mathrm{n}=44)$ was significantly greater than that of non-smokers $(0.75$ $(0.20) \mathrm{pmol} / \mathrm{ml}, \mathrm{n}=40, \mathrm{P}<0.005$ by $t$ test). We also compared urinary 1-OHPG concentrations of workers in each of the seven different job categories within the plant (fig 3). All but two workers in the blast furnace or coke plant categories had 1-OHPG concentrations higher than $2 \mathrm{pmol} / \mathrm{ml}$, whereas all office

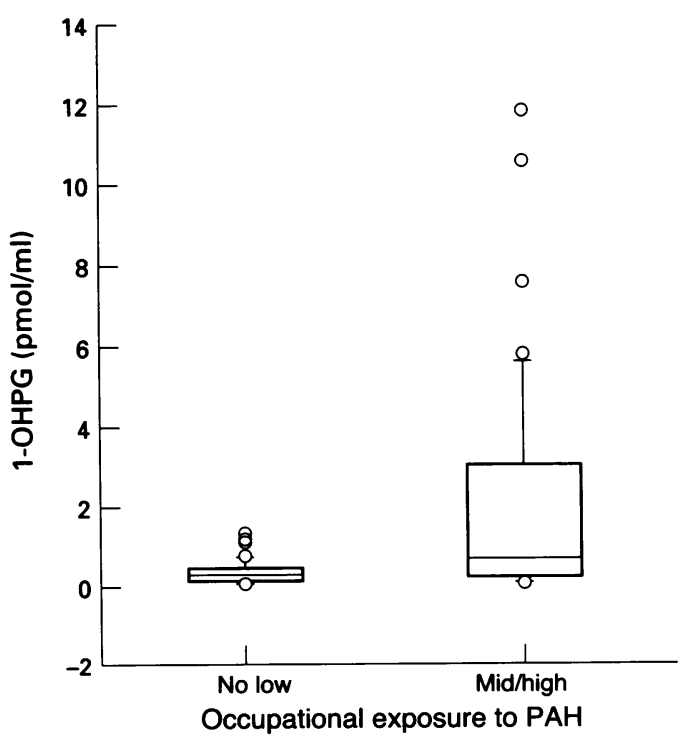

Figure 2 Box and whisker plot of urinary 1-OHPG concentrations by occupational $P A H$ exposure group. Lowest whisker $=10$ th percentile; lower edge of box $=25$ th percentile; middle line of box $=50$ th percentile; upper edge of box $=75$ th percentile; highest whisker $=90$ th percentile of the data. 
Figure 3 Box and whisker plot of urinary 1-OHPG concentrations by job category.

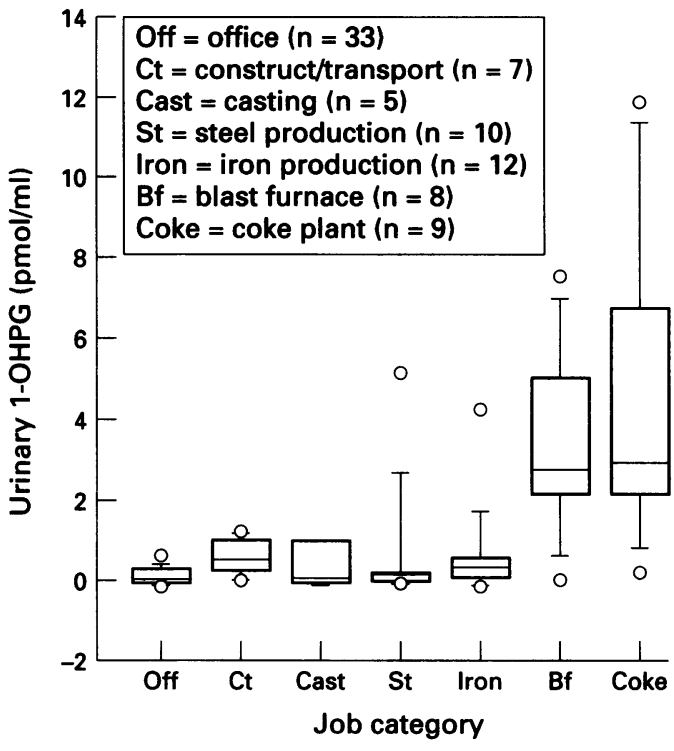

workers had concentrations lower than 1 $\mathrm{pmol} / \mathrm{ml}$. Overall, there was a significant difference in 1-OHPG concentrations between job categories $(P<0.0001$, by ANOVA). Mean 1-OHPG concentrations in either blast furnace or coke oven workers were higher than mean concentrations in each of the other five job categories $(P<0.05$ by Duncan's multiple range). Similarly, mean 1-OHPG concentration in the 33 office workers was lower than in each of the other six job categories, including the seven construction or transportation workers $(P<0.05$ by Duncan's multiple range test).

To examine the dose-response relation between 1-OHPG and PAH exposure, we tested the correlation between strata of PAH exposure and 1-OHPG. A highly significant correlation between exposure strata (no or low, mid, or high) and 1-OHPG was found (Pearson $r=0.65, P<0.0001$ ). The combined effect of smoking and occupation on 1OHPG concentrations was examined by

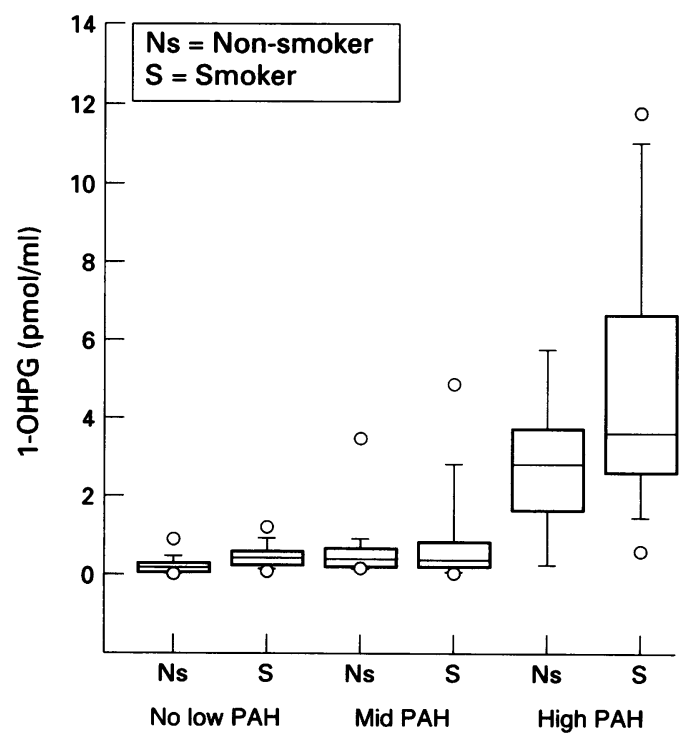

categorising the three occupational PAH exposure strata by smoking group (fig 4). Mean 1-OHPG concentrations in smokers were greater than for non-smokers in the same PAH exposure stratum (table 3 ). The absolute difference in 1-OHPG concentrations $(2.07 \mathrm{pmol} / \mathrm{ml})$ between smokers and non-smokers in the high PAH exposure group was greater than the difference in 1-OHPG concentrations between smokers and nonsmokers in either the mid PAH exposure group $(0.24 \mathrm{pmol} / \mathrm{ml})$ or the no or low exposure group $(0.25 \mathrm{pmol} / \mathrm{ml})$. Although this is consistent with an interactive effect between smoking and occupational exposure to PAHs, the test for interaction by linear regression was not significant $(P=0 \cdot 30)$. We had limited power to evaluate this interaction because 12 of $17(71 \%)$ workers in the high PAH exposure stratum were current smokers, leaving only five non-smokers for comparison.

Multiple regression analysis indicated that both occupational exposure to PAHs and smoking were significant predictors of urinary 1-OHPG concentrations (table 4). The overall model $r^{2}$ was 0.55 , indicating that $55 \%$ of the variation of $1-O H P G$ concentration was explained by the variables smoking and occupational exposure to PAHs. Similar results were obtained after adjustment for age or urinary creatinine.

Table 3 Urinary 1-OHPG concentration by PAH exposure strata

\begin{tabular}{|c|c|c|c|}
\hline & \multicolumn{3}{|c|}{$P A H$ exposure strata } \\
\hline & $\begin{array}{l}\text { No or low } \\
(n=40)\end{array}$ & $\begin{array}{l}\text { Mid } \\
(n=27)\end{array}$ & $\begin{array}{l}\text { High } \\
(n=17)\end{array}$ \\
\hline $\begin{array}{l}\text { Smoking: } \\
\text { Never or ex: } \\
\text { n } \\
\text { mean (SEM) } \\
(\mathrm{pmol} / \mathrm{ml})\end{array}$ & $\begin{array}{l}20 \\
0.26(0.06)\end{array}$ & $\begin{array}{l}15 \\
0 \cdot 70(0 \cdot 28)\end{array}$ & $\begin{array}{l}5 \\
2.84(0.90)\end{array}$ \\
\hline $\begin{array}{l}\text { Current: } \\
\text { n } \\
\text { mean (SEM) } \\
(\mathrm{pmol} / \mathrm{ml})\end{array}$ & $\begin{array}{l}20 \\
0.55(0.07)\end{array}$ & $\begin{array}{l}12 \\
0.94(0.42)\end{array}$ & $\begin{array}{l}12 \\
4 \cdot 91(1 \cdot 02)\end{array}$ \\
\hline
\end{tabular}

Table 4 Predictors of urinary 1-OHPG by multiple linear regression

\begin{tabular}{|c|c|c|c|}
\hline$\underline{\text { Variable }}$ & $\beta(S E \beta)^{\star}$ & Pvalue & $\begin{array}{l}\text { Overall } \\
\text { model }\left(r^{2}\right)\end{array}$ \\
\hline $\begin{array}{l}\text { Model A: } \\
\text { Intercept } \\
\text { PAH exposure1 } \downarrow \\
\text { PAH exposure2 } \ddagger\end{array}$ & $\begin{aligned} &-1.29 \\
& 0.49(0.23) \\
& 2.43(0.27)\end{aligned}$ & $\begin{array}{c}0.036 \\
<0.0001\end{array}$ & 0.51 \\
\hline $\begin{array}{l}\text { Model B: } \\
\text { Intercept } \\
\text { Smoking (yes or no) }\end{array}$ & $\begin{array}{r}-1.07 \\
0.81(0.27)\end{array}$ & 0.0037 & 0.098 \\
\hline $\begin{array}{l}\text { Model C: } \\
\text { Intercept } \\
\text { PAH exposure1 } 1 \\
\text { PAH exposure2 } \\
\text { Smoking (Yes or no) }\end{array}$ & $\begin{array}{r}-1.55 \\
0.52(0.22) \\
2.32(0.26) \\
0.52(0.20)\end{array}$ & $\begin{array}{c}0.022 \\
<0.0001 \\
0.01\end{array}$ & 0.55 \\
\hline $\begin{array}{l}\text { Model C (creatinine ad } \\
\text { Intercept } \\
\text { PAH exposure } 1 \dagger \\
\text { PAH exposure } \ddagger \\
\text { Smoking (Yes or no) }\end{array}$ & $\begin{array}{l}\text { djusted): } \\
-3 \cdot 38 \\
0 \cdot 62(0 \cdot 25) \\
2 \cdot 13(0 \cdot 29) \\
0.46(0 \cdot 22)\end{array}$ & $\begin{array}{l}0.015 \\
<0.0001 \\
0.04\end{array}$ & $0 \cdot 44$ \\
\hline
\end{tabular}
whisker plot of urinary 1-OHPG concentrations stratified by smoking and $P A H$ exposure strata. 
The dose-response relation of cigarette smoking with concentration of 1-OHPG was examined by testing the association between number of cigarettes smoked a day and 1OHPG concentrations. Overall, there was a significant association between 1-OHPG concentration and number of cigarettes smoked (Pearson's $r=0.28, \mathrm{P}<0.01, \mathrm{n}=82$; two missing, data not shown). When examined by PAH exposure strata, there was a significant association between concentration of 1OHPG and number of cigarettes smoked in the no or low PAH exposure stratum (Pearson's $r=0.44, \mathrm{P}<0.004, \mathrm{n}=40$ ) but not the combined mid and high PAH exposure stratum (Pearson's $r=0 \cdot 26, \mathrm{P}=$ $0 \cdot 09, \mathrm{n}=42$ ). To evaluate the sensitivity of the assay to detect moderate concentrations of smoking, we compared 1-OHPG in nonsmokers and those who smoked $\leqslant 20$ cigarettes a day (mean cigarettes a day $=15$; range = 7-20) in the no PAH exposure stratum (office workers only). A significant difference in 1-OHPG concentrations was found between the 17 non-smokers $(0.20 \quad(0.04)$ $\mathrm{pmol} / \mathrm{ml})$ and the 15 moderate smokers $(0.41$ $(0.05) \mathrm{pmol} / \mathrm{ml}, \mathrm{P}=0.003$, by $t$ test).

The association between 1-OHPG concentrations and dietary $\mathrm{PAH}$ exposure was assessed with data on consumption of foods containing high concentrations of PAHs from the dietary questionnaire. Among this population of workers, relatively small quantities of foods known to contain high PAH concentrations were consumed. Fifteen of 84 study subjects had consumed small amounts of grilled or broiled meat within the two weeks before sample collection; however, only five of these subjects had consumed it within 48 hours of collection. Thus we could only compare 1OHPG concentrations between those workers with low dietary PAH exposure $(n=15)$ and those with no dietary PAH exposure $(n=69)$. No significant difference was found between these groups; therefore, diet did not seem to significantly contribute to urinary $1-O H P G$ in this population.

\section{Discussion}

We examined 1-OHPG concentration in urine from 44 workers with jobs in areas of increased PAH concentrations in air and 40 workers with jobs at the same site with low or no exposure to PAHs. Mean 1-OHPG concentration in exposed workers was significantly increased compared with unexposed controls. We also compared urinary 1-OHPG concentrations of workers in each of the seven different job categories within the plant. There was a significant difference in log transformed 1-OHPG concentrations between job categories. Mean 1-OHPG concentrations in the blast furnace and coke oven workers were significantly increased compared with workers in other job categories.

Assignment of exposure strata for PAHs based on job category was used to investigate the association of urinary 1-OHPG with PAH exposure. A clear dose-response relation was found between mean 1-OHPG concentrations and no or low, mid, and high PAH exposure strata in both the current smokers and the non-smokers. The correlation between PAH exposure strata and 1-OHPG was highly significant (Pearson $r=0.65, \mathrm{P}<$ 0.0001 ). Also, 1-OHPG concentration was correlated with quantity of cigarettes smoked among all workers or among no or low exposed workers. Thus, both smoking and occupational exposure to PAHs was associated with increased concentrations of 1OHPG in urine from steel plant workers. This was verified by regression analysis.

We have chosen not to adjust our 1-OHPG values for urinary creatinine as this had little effect on the analyses or our conclusions. Also, deletion of samples with creatinine values $<4.0 \mu \mathrm{mol} / \mathrm{ml}$ urine as suggested, ${ }^{9}$ left associations with occupational exposures unchanged and only slightly strengthened most associations with smoking. In previous studies of urinary 1-OHPG after dietary PAH exposure ${ }^{24}$ or smoking (unpublished), we have found no improvement of associations between 1-OHPG and PAH exposure after adjustment for creatinine.

Although concurrent PAH exposure data were not available, job category was used to construct relative exposure strata. Measurements of benzene soluble fractions in personal air samples were available from one year before urine collection in the coke oven workers only. Mean concentrations of benzene soluble fractions were $0.24-0.49 \mathrm{mg} / \mathrm{m}^{3}$ for three high exposure job titles in the coke oven battery. This range is below the published mean value of $2.08 \mathrm{mg} / \mathrm{m}^{3}$ from personal samples that represents 11 job titles at 10 coke plants measured $25-30$ years ago. ${ }^{20} \mathrm{~A}$ more recent study reported mean values of 0.3 and $0.5 \mathrm{mg} / \mathrm{m}^{3}$ (individual range: $<0.1-$ $5 \cdot 7$ ) among 16 highly exposed workers at two coke ovens. ${ }^{21}$ The corresponding mean benzo(a)pyrene concentrations measured in those samples were $0 \cdot 7$ and 1.2 (individual range: $0 \cdot 1-6 \cdot 5) \mu \mathrm{g} / \mathrm{m}^{3}$.

Assessment of urinary 1-hydroxypyrene has been applied in populations exposed to PAHs from different sources (occupation, therapy, and food). Recent reports of 1-hydroxypyrene in human urine indicate that early studies may have overestimated the amount of 1-hydroxypyrene. $^{22}{ }^{23}$ Concentrations of 1-hydroxypyrene in human urine from people with similar occupational exposures vary widely in different studies. These results indicate that considerable variability occurs in these measurements when performed by different investigators at different worksites. The basis for this variability (laboratory, exposure, or biological) is unclear at the present time.

Although it is difficult to directly compare urinary 1-OHPG concentrations in this study with the values of other occupational exposure studies because 1-hydroxypyrene has been measured in most studies, the mean (range) urinary concentration of 1-OHPG adjusted for creatinine among non-smoking office workers in this study $(0.05(0.004-0.16)$ 
$\mu \mathrm{mol} / \mathrm{mol}$ creatinine, $\mathrm{n}=17$ ) was comparable with 1-hydroxypyrene concentrations of nonsmoking controls reported in several other studies: $0.17(0.01-0.93) \mu \mathrm{mol} / \mathrm{ml}$ creatinine, $\mathrm{n}=14^{9} ; 0.16(0.10-0.22) \mu \mathrm{mol} / \mathrm{mol}$ creatinine, $\mathrm{n}=20^{22}$; and $0.26(0.02-0.66) \mu \mathrm{mol} /$ mol creatinine, $\mathrm{n}=52 .{ }^{10} \mathrm{~A}$ more recent study reported lower concentrations of urinary 1hydroxypyrene in 43 non-smoking controls: $0-0.01 \mu \mathrm{mol} / \mathrm{mol}$ creatinine $(10-90$ percentiles). ${ }^{23}$ The similarly low urinary $1-O H P G$ concentrations among non-smoking controls in our study might be due to low dietary consumption of PAHs. Amounts of foods ingested by this group of workers that contained PAHs were relatively low and did not contribute significantly to urinary 1-OHPG concentrations. Infrequent consumption of foods with a high PAH content, such as smoked or broiled foods, is characteristic of the Korean diet. Dietary information collected by questionnaire indicated that relatively little broiled, smoked, or grilled meat was consumed by the subjects in the present study. Furthermore, the mean urinary 1OHPG concentration among non-smoking office workers in this study was comparable to the mean concentration in urine samples from workers on a controlled diet that contained very low concentrations of PAHs. ${ }^{24}$ Mean 1OHPG concentrations in non-smokers adjusted for creatinine were $0.05,0.15,0.37$ (range of high $\mathrm{PAH}$ exposure group, $0.02-0.89) \mu \mathrm{mol} / \mathrm{mol}$ creatinine for the no or low, mid, and high PAH exposure groups based on job category. The corresponding values in smokers were $0.06,0.19,0.82$ (range of high $\mathrm{PAH}$ exposure group, $0 \cdot 15-3.57) \mu \mathrm{mol} / \mathrm{mol}$ creatinine, respectively. Mean 1-OHPG concentration in our group of smokers with high exposure to PAHs was similar to that found previously in bench side coke oven workers, ${ }^{25}$ in smokers exposed to diesel exhaust, ${ }^{12}$ in road pavers, ${ }^{12}$ and in foundry workers. ${ }^{26}$ The results in this study are, however, generally lower than the values reported in studies with moderate to high PAH exposure: in highly exposed coke oven workers, ${ }^{25}$ in aluminum reduction plant workers, ${ }^{27} 28$ and in coal tar distillation plant workers. ${ }^{10}$ These differences may be due to a variety of factors including $(a)$ differences in exposure concentrations between steel plants, (b) metabolic differences between the subjects studied, (c) differences in assay conditions and accuracy, or (d) bias associated with creatinine normalisation. Relative differences in 1OHPG concentrations between controls and coke oven workers are comparable with those found in other studies. The 11-fold difference in urinary 1-OHPG concentrations found between office workers and coke plant workers is consistent with the results of Jongeneelen et $a l^{9}$ who showed a 10-fold difference between non-smoking controls and coke oven workers, and a sixfold difference between controls and coke oven workers who smoked.

In this study, smokers had consistently higher urinary 1-OHPG concentrations than non-smokers. The amount of pyrene in one cigarette is $50-200 \mathrm{ng}(230-917 \mathrm{pmol})$. Therefore, smoking 10 cigarettes a day would yield a maximum daily inhaled dose of about $2 \cdot 3-9 \cdot 2 \mathrm{nmol}$. The estimated increase in urinary 1-OHPG concentration from such a dose would be about $0.1 \mathrm{nmol} / 1$ urine, calculated from the linear regression model. This suggests that on average about $1 \%-4 \%$ of the pyrene inhaled from cigarette smoke is excreted as 1-OHPG in urine assuming a daily urinary volume of 1 litre.

In summary, there are several potential applications of an assay for urinary 1-OHPG. Firstly, although the proportion of pyrene in different working environments varies from $2 \%$ to $20 \%$ of the total PAHs, several studies have reported fairly constant ratios of pyrene to other PAHs in specific work environments such as coke plants ${ }^{925}$ or aluminum plants. ${ }^{27}$ Therefore the measurement of 1-OHPG may be useful in assessment of exposure to total PAHs in these types of plants. Secondly, although excretion of 1-hydroxypyrene occurs fairly rapidly after exposure $\left(6-35 h^{9}\right.$ ) and excretion of 1-OHPG declines to near baseline concentrations within 48 hours of the end of dietary exposure, ${ }^{24}$ this metabolite could prove useful as a component of medical biomonitoring in the workplace. The advantages of simplicity and rapidity of the assay and the ready availability and non-invasiveness of specimen collection make the assay amenable to routine sampling. Thirdly, the assay could also be used to complement air monitoring data when evaluating the effectiveness of new interventions, engineering control devices, or personal protective equipment in the working environment. ${ }^{29}$ Fourthly, these and other urinary $\mathrm{PAH}$ metabolites may prove to be useful in assessing human PAH exposure from multiple sources when different kinetics for inhaled or ingested PAHs must be considered in exposure assessment or when estimation of external exposure concentrations is difficult. The biological implications of increased urinary 1-OHPG concentrations should be explored in the future in prospective cohort studies that have banked urine samples.

We gratefully acknowledge the participation of the study subjects. This research was supported in part by DHHS grants P30-ES03819 and P01-ES06052.

1 Grimmer G. Sources and occurrence of polycyclic aromatic hydrocarbons. In: Environmental carcinogen selected methods of analysis. Vol 3. Analysis of polycyclic aromatic hydrocarbons in environmental samples. IARC Sci Publ 1979;29:31-54.

2 International Agency for Research on Cancer. LARC monographs on the evaluation of the carcinogenic risk of chemicals to humans: polymuclear aromatic compounds, part 1 .Volume 32. Lyon: IARC, 1983.

3 Bjørseth A, Becher G. PAH in work atmosphere: occurrence and determination. Boca Raton: CRC Press, 1986:137.

4 Becher G, Bjorseth A. Determination of exposure to polycyclic aromatic hydrocarbons by analysis of human cyclic aromatic hydrocarbons by
urine. Cancer Lett 1983;17:301-11.

5 Venier P, Clonfero E, Cottica D, Gava C, Zordan M, Pozzoli L, et al. Mutagenic activity and polycyclic Pozzoli $\mathrm{L}$ et al. Mutagenic activity and polycyclic
aromatic hydrocarbon levels in urine of workers exposed to coal tar pitch volatile in an anode plant. Carcinogenesis 1985;6:749-52.

6 Haugen A, Becher G, Benestad C, Vahakangas $K$, Trivers $\mathrm{GE}$, Newman MJ, et al. Determination of polycyclic 
aromatic hydrocarbons in the urine, benzo(a)pyrene diol epoxide-DNA adducts in lymphocyte DNA, and antibodies to the adducts in sera from coke oven workers exposed to measured amounts of polycyclic aromatic hydrocarbons in the work atmosphere. Cancer Res 1986; 46:4178-83.

7 Keimig SD, Kirby KW, Morgan DP, Keiser JE, Hubert TD. Identification of 1-hydroxypyrene as a major 415-20.

8 Jongeneelen FJ, Bos RP, Grimmer G. Excretion of pyrene and hydroxypyrene in urine [letter]. Cancer Lett 1990;51: 175-9.

9 Jongeneelen FJ, van Leeuwen FE, Oosterink S, Anzion RBM, van der Loop F, Bos RP, et al. Ambient and biological monitoring of coke oven workers: determinants of the internal dose of polycyclic

10 Jongeneelen FJ, Anzion RBM, Scheepers PTJ, Bos RP, Henderson PTh, Nijenhuis EH, et al. 1-Hydoxypyrene in urine a biological indicator of exposure to polycyclic aromatic hydrocarbons in several work environments. Ann Occup Hyg 1988;32:35-43.

11 Jongeneelen FJ, Scheepers PTJ, Groenendijk A, Van Aerts L, Anzion RBM, Bos RP, et al. Airborne concentration of polycyclic aromatic hydrocarbons among paving workers exposed to coal tar derived road tars. Am Ind wyg Assoc $\mathcal{F} 1988 ; 49: 600-7$.

12 Jongeneelen FJ, Anzion RBM, Henderson PT. Determination of hydroxylated metabolites of polycyclic aromatic ation of hydroxylated metabolites of polycyclic aromatic

13 Jongeneelen FJ, Bos RP, Anzion RBM, Thews JLG, Henderson PT. Biological monitoring of polycyclic aromatic hydrocarbons: metabolites in urine. Scand $\mathcal{F}$ Work Environ Health 1986;12:137-43.

14 Jongeneelen FJ, Leijdekkers CM, Bos RP, Theuws LG, Henderson PT. Excretion of 3-hydroxy-benzo[a] pyrene and mutagenicity in rat urine after exposure to benzo[a]pyrene. I Appl Toxicol 1985;5:277-82.

15 Jongeneelen FJ, Anzion RBM, Leijdekkers CM, Bos RP, Henderson PT. 1-Hydroxypyrene in human urine after exposure to coal tar and a coal tar derived product. Int Arch Occup Environ Health 1985;57:47-55.

16 Clonfero E, Zordan M, Venier P, Paleologo M, Levis AG, Cottica D, et al. Biological monitoring of human exposure to coal tar. Urinary excretion of total polycyclic arosure to coal tar. Urinary excretion of total polycyclic aro-
matic hydrocarbons, 1-hydroxypyrene and mutagens in matic hydrocarbons, 1-hydroxypyrene and mutagens in psoriatic pat

17 Strickland PT, Kang DH, Bowman ED, Fitzwilliam A, Downing TE, Rothman N, et al. Identification of 1hydroxypyrene-glucuronide as a major pyrene metabolite in human urine by synchronous fluorescence spectroscopy and gas chromatography/mass spectrometry. Carcinogenesis 1994;15:483-7.

18 International Agency for Research on Cancer. IARC mono- graphs on the evaluation of the carcinogenic risk of chemicals to humans: polymuclear aromatic compounds, part 3. Vol 34. Lyon: IARC,1984:101-90.

19 Santella RM, Lin CD, Cleveland WL, Weinstein IB. Monoclonal antibodies to DNA modified by a benzo[a]pyrene diol epoxide. Carcinogenesis 1984;5: 373-7.

20 Fannick N, Gonshor LT, Shockley Jr. Exposure to coal tar pitch volatiles at coke ovens. Am Ind Hyg Assoc 7 1972;33:461-8.

21 Jongeneelen FJ. Biological exposure limit for occupational exposure to coal tar pitch volatiles at coke ovens. Int Arch Occup Environ Health 1992; 63:511-6.

22 Sherson D, Sigsgaard T, Overgaard E, Loft S, Poulsen $\mathrm{HE}$, Jongeneelen FJ. Interaction of smoking, uptake of polycyclic aromatic hydrocarbons, and cytochrome polycyclic aromatic hydrocarbons, and cytochrome 1992;49:197-202.

23 Omland O, Sherson D, Hansen AM, Sigsgaard T, Autrup $\mathrm{H}$, Overgaard E. Exposure of iron foundry workers to polycyclic aromatic hydrocarbons: benzo(a)pyrenealbumin adducts and 1-hydroxypyrene as biomarkers for exposure. Occup Environ Med 1994;51:513-8.

24 Kang DH, Rothman N, Poirier MC, Greenberg A, Hsu $\mathrm{CH}$, Schwartz BS, et al. Inter-individual differences in the concentration of 1-hydroxypyrene-glucuronide in urine and polycyclic aromatic hydrocarbon-DNA adducts in peripheral white blood cells after charbroiled beef consumption. Carcinogenesis 1995;16:1079-85.

25 Buchet JP, Gennart JP, Mercado-Calderon F, Delavignette JP, Cupers L, Lauwerys R. Evaluation of Delavignette JP, Cupers L, Lauwerys $R$. Evaluation of
exposure to polycyclic aromatic hydrocarbons in a coke production and graphite electrode manufacturing plant: production and graphite electrode manufacturing plant: assessment of urinary excretion of 1-hydroxypyrene as a biological

26 Santella RM, Hemminki K, Tang D, Paik M, Ottman R, Young TL, et al. PAH-DNA adducts in white blood cells and urinary 1-hydroxypyrene in foundry workers. Cancer Epidemiol Biomarkers Prev 1993;2:59-62.

27 Tolos WP, Shaw PB, Lowry LK, Mackenzie BA, Deng JF, Markel HL. 1-Pyrenol: a biomarker for occupational exposure to polycyclic aromatic hydrocarbons. $A p p l$ Occup Environ Hyg 1990;5:303-9.

28 Van Schooten FJ, Jongeneelen FJ, Hillebrand MJX, van Leeuwen FE, de Looff AJA, Dijkmans APG, et al. Leeuwen FE, de Looff AJA, Dijkmans APG, et al. blood cell DNA and 1-hydroxypyrene in the urine from blood cell DNA and 1-hydroxypyrene in the urine from
aluminum workers: relation with job category and syneraluminum workers: relation with job category and syner-
gistic effect of smoking. Cancer Epidemiol Biomarkers Prev gistic effect of

29 Van Rooij JGM, Van Lieshout MAV, Bodelier-Bade MM, Jongeneelen FJ. Effect of the reduction of skin contamination on the internal dose of creosote workers exposed to polycyclic aromatic hydrocarbons. Scand F Work Environ Health 1993;19:200-7. 